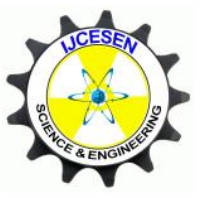

Copyright (C) IJCESEN
International Journal of Computational and

Experimental $\boldsymbol{S}$ cience and Engineering

(IJCESEN)

Vol. 4-No.2 (2018) pp. 32-36

http://dergipark.gov.tr/ijcesen

Research Article

\title{
A Project Management Model for Assessment of a Construction Project
}

\author{
Murat ÇOLAK ${ }^{1}$, Şeyma KESİK ${ }^{1}$, Utkan MUTMAN ${ }^{2}$, Gülşen AYDIN KESKİN ${ }^{1}$ * \\ ${ }^{1}$ Kocaeli University, Engineering Faculty, Industrial Engineering Department, 41380, Kocaeli-Turkey \\ ${ }^{2}$ Kocaeli University, Engineering Faculty, Civil Engineering Department, 41380, Kocaeli-Turkey \\ * Corresponding Author : gaydin@kocaeli.edu.tr \\ ORCID: 0000-0001-6639-1882
}

(First received on 17 April 2018 and final form in 14 May 2018)

\section{Keywords \\ Project Management PERT \\ Project Crashing \\ Construction Sector}

\begin{abstract}
Various projects are realized by private sector and public institutions in recent days. Machine, material, manpower, time and money are the main resources required for these projects. Since, each one is a cost item, these sources should be used effectively in order to provide competitive advantage in the project planning process. In this context, an efficient project management system provides effective usage of resources, good working environment and timely completion of projects. Critical Path Method (CPM) and Program Evaluation and Review Technique (PERT) are utilized as project planning methods in order to determine the completion time of projects. On the other hand, it can be possible to complete a project earlier using additional sources with project crashing approach. In this study, initially activities and durations for a construction project realized in Kocaeli have been determined. Afterwards, expected completion time, critical activities and critical path have been determined for this project. In the second phase, project crashing cost for critical activities has been calculated through a mathematical model. Thus, the applicability of the project management model has been revealed.
\end{abstract}

\section{Introduction}

Project concept is generally defined as temporary and intensive efforts in order to develop a product or service. Time, money, workforce, material and machine can be ranked as the main sources for any project and it is important to use these sources effectively. Project management is also defined as planning, managing and controlling manpower, machine and material in order to complete the project at desired conditions by considering time, cost and technical situations.

CPM and PERT methods developed in the late 1950s are utilized as project planning techniques for an effective project management system. CPM can be applied so as to determine the time required to complete a project, when the duration of each activity is known as deterministic. PERT can be used in order to estimate the probability for completing a project by a given deadline. Scheduling construction projects, building a ship and designing and marketing a new product can be given as examples

for application areas of CPM and PERT methods. In many situations, it can be necessary to complete projects earlier than the time of the critical path. It is possible to calculate the crashing cost via mathematical models in these cases [1].

There are many factors affecting the successful completion of construction projects due to complexity of these projects. Although project managers believe to apply right methods, some problems can occur in construction projects according to 2015 Global Construction Project Owner's Survey [2]. Therefore, it is necessary to handle these projects with efficient project management models. On the other hand, cost overrun is another problem in construction industry. Cost estimation techniques can be used for construction projects as effective tools [3]. Besides, mathematical models are also utilized for cost 
management in project planning in order to obtain optimum solution. In addition, meta-heuristic algorithms such as genetic algorithm (GA) and Particle Swarm Optimization (PSO) give suitable solutions for NP-hard problems [4].

In this study, a project management model has been presented for a construction project in order to determine expected completion time and project crashing cost. The rest of paper is organized as follows. In section 2, a literature review for studies related to project management and project crashing is presented. In section 3, the case study for a construction project is presented. Conclusions and future research suggestions are given in Section 4.

\section{Literature Review}

Foldes and Soumis [5], presented a new generalization of PERT by considering task durations as variable. They handled cost of each task as a convex function of related task. Shipley et al. [6], developed Belief in Fuzzy Probablity Estimations of Time (BIFPET) model as a project management tool in order to determine project completion time using human judgments. Gümüsoglu and Tütek [7], introduced a novel method via linear programming (LP) model using primal dual relationships for project planning and showed the effectiveness of the proposed method through a case study. Abbasi and Mukattash [8], developed a method in order to examine the application of project crashing concept in PERT. Yang [9], presented an approach using PSO algorithm for project crashing. Trietsch and Baker [10], developed PERT 21 method in order to provide different stochastic analysis for projects by improving existing CPM and PERT methods. Cebi and Otay [11], presented a multi-objective mathematical programming model so as to handle project network problem under fuzzy environment. This model includes minimizing project completion time and minimizing total project cost objectives. Tabrizi and Ghaderi [12], developed a robust biobjective model in order to realize project scheduling and material procurement concurrently. Lee et al. [13], presented a project management model for constructing a renewable energy plant in Taiwan. In the first phase, they calculated completion time and total cost for this project. Afterwards, they calculated completion time and total cost again by crashing some activities. Besides, they applied fuzzy PERT so as to obtain more sensitive results. Soto et al. [14], proposed a new methodology including determination of optimal schedules for construction project by means of Tabu Search and integration of project visualizations.

\section{A Real Case Application}

A transformer building project of a tramline realized in Kocaeli was analyzed as a case study in this section. Firstly, 21 activities and their three time estimates are defined for this project. Afterwards, expected completion time and critical activities were determined. Activities and predecessors, three time estimates and costs of them are given in Table 1. Activity on Arc (AOA) network for this construction project is presented in Figure

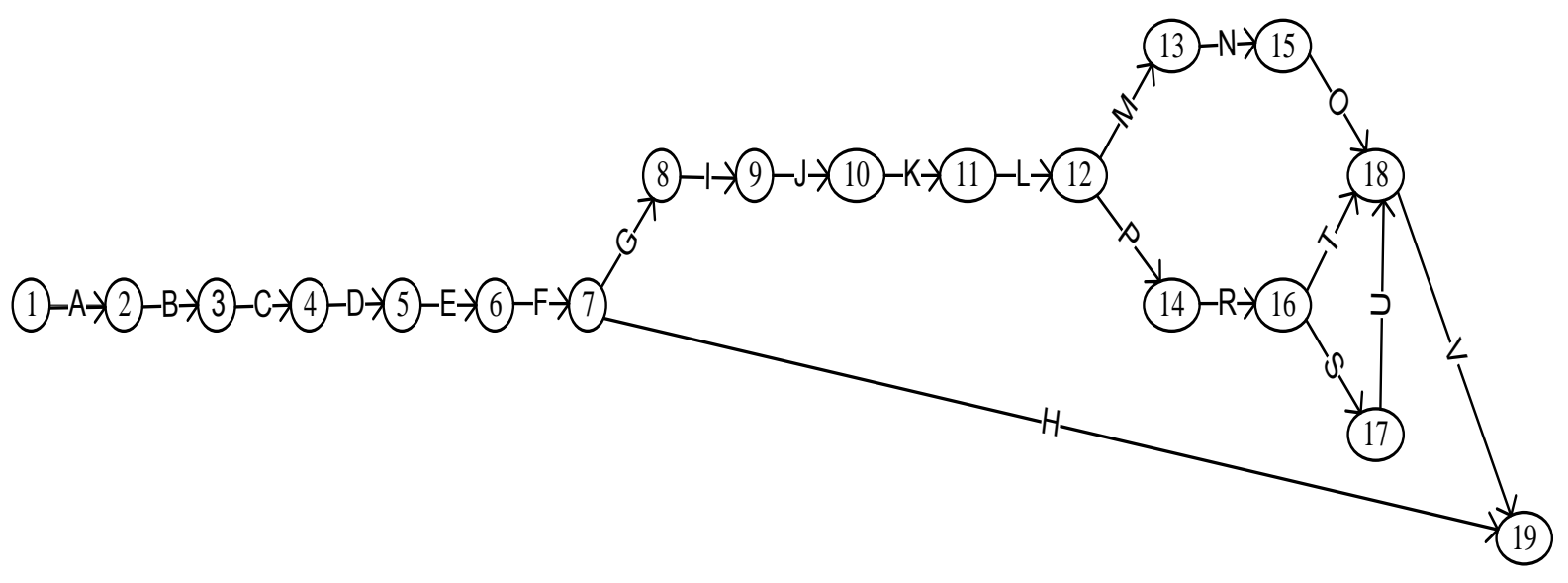

Figure 1. Activity on Arc (AOA) network for the construction project 
Table 1. Project activities, predecessors, three time estimates and costs

\begin{tabular}{|c|l|c|c|c|c|}
\hline No & \multicolumn{1}{|c|}{ Activity (Act) } & Code & $\begin{array}{c}\text { Predecessor } \\
\text { Activity }\end{array}$ & $\begin{array}{c}\text { (a,m,b) } \\
\text { (day) }\end{array}$ & $\begin{array}{c}\text { Cost } \\
\text { (TRY) }\end{array}$ \\
\hline 1 & Excavation & $\mathrm{A}$ & -- & $(3,5,6)$ & 8350 \\
\hline 2 & Lean Concrete & $\mathrm{B}$ & $\mathrm{A}$ & $(0.3,0.5,1)$ & 3400 \\
\hline 3 & $\begin{array}{l}\text { Laying a foundation protective membrane and preservative lean } \\
\text { concrete pouring over insulation }\end{array}$ & $\mathrm{C}$ & $\mathrm{B}$ & $(1,2,4)$ & 9800 \\
\hline 4 & Raft foundation formwork, iron and concrete works & $\mathrm{D}$ & $\mathrm{C}$ & $(6,7,10)$ & 31400 \\
\hline 5 & $\begin{array}{l}\text { Basement floor column and curtain formwork, iron and } \\
\text { concrete works }\end{array}$ & $\mathrm{E}$ & $\mathrm{D}$ & $(5,6,10)$ & 28000 \\
\hline 6 & $\begin{array}{l}\text { Basement floor beams and deck formwork, iron and concrete } \\
\text { works }\end{array}$ & $\mathrm{F}$ & $\mathrm{E}$ & $(4,5,8)$ & 20800 \\
\hline 7 & Screed and surface hardener & $\mathrm{G}$ & $\mathrm{F}$ & $(3,4,5)$ & 8150 \\
\hline 8 & Drenflex and filling process & $\mathrm{H}$ & $\mathrm{F}$ & $(1.5,2,2.5)$ & 10500 \\
\hline 9 & Ground floor columns irons, formwork and concrete works & $\mathrm{I}$ & $\mathrm{G}$ & $(3,4,7)$ & 8700 \\
\hline 10 & Ground floor deck formwork ribbed beams and iron works & $\mathrm{J}$ & $\mathrm{I}$ & $(4,5.5,7)$ & 18850 \\
\hline 11 & Ground floor deck to manufacture hollow & $\mathrm{K}$ & $\mathrm{J}$ & $(0.5,1,2)$ & 2670 \\
\hline 12 & Iron and concrete works on ground floor & $\mathrm{L}$ & $\mathrm{K}$ & $(0.5,1,2)$ & 8300 \\
\hline 13 & Waterproofing on ground floor concrete & $\mathrm{M}$ & $\mathrm{L}$ & $(1,2,3)$ & 4000 \\
\hline 14 & Protective concrete on the ground floor deck & $\mathrm{N}$ & $\mathrm{M}$ & $(0.3,0.5,1)$ & 1850 \\
\hline 15 & Roof parapet iron, concrete work and coping & $\mathrm{O}$ & $\mathrm{N}$ & $(1,2,3)$ & 1400 \\
\hline 16 & Ground floor bricklaying process & $\mathrm{P}$ & $\mathrm{L}$ & $(2,3,4)$ & 9150 \\
\hline 17 & Rough cast & $\mathrm{R}$ & $\mathrm{P}$ & $(3,4,5)$ & 20500 \\
\hline 18 & Manufactureing of doors and air vents & $\mathrm{S}$ & $\mathrm{R}$ & $(0.3,0.5,1)$ & 2340 \\
\hline 19 & Internal plaster and water-based semi-gloss done twice & $\mathrm{T}$ & $\mathrm{R}$ & $(3,4,6)$ & 15930 \\
\hline 20 & Exterior acrylic paints & $\mathrm{U}$ & $\mathrm{T}$ & $(1,2,3)$ & 7500 \\
\hline 21 & Rain downpipe arrangement & $\mathrm{V}$ & $\mathrm{O}, \mathrm{T}, \mathrm{U}$ & $(0.5,1,1.5)$ & 80 \\
\hline
\end{tabular}

The expected completion time of the project was calculated by using a mathematical model. Decision variables, objective function and constraints of this model are given as follows:

Indices:

$\mathrm{W}=\{1,2, \ldots, 19\}$

$\mathrm{Q}=\{A, B, C, D, E, F, G, H, I, J, K, L, M, N, O, P, R, S, T, U, V\}$

$j$ : Nodes $\quad \forall j \in W$

$i$ :Activities $\quad \forall i \in Q$

Decision variables:

$X_{j}$ : the time that the event corresponding to node $\mathrm{j}$ occurs $t_{i j}$ : the duration of activity on arc $(i, j)$

Objective Function:

$\min \quad z \quad \begin{array}{llll}x_{L} & - & x_{1}\end{array}$

(1)

Constraints:

$x_{j} \geq x_{i}+t_{i j}$

(2)

The objective function which aims to minimize the time between the last and the first nodes is given in
Equation 1. According to constraint 2, the time of node $\mathrm{j}$ must be greater than or equal to total time of node $i$ and related activity. The results of mathematical model obtained from LINGO 17.0 program are given in Table 2. As seen in this table, expected completion time of the project is determined as 54.9 days.

Table 2. Results of the mathematical programming model

\begin{tabular}{|c|c|c|c|}
\hline Objective Value & 54.9 & \multicolumn{2}{|c|}{} \\
\hline Variable & Value & Variable & Value \\
\hline$x_{19}$ & 54.9 & $x_{10}$ & 40.50 \\
\hline$x_{1}$ & 0 & $x_{11}$ & 41.60 \\
\hline$x_{2}$ & 4.80 & $x_{12}$ & 42.70 \\
\hline$x_{3}$ & 5.40 & $x_{13}$ & 44.70 \\
\hline$x_{4}$ & 7.60 & $x_{14}$ & 45.70 \\
\hline$x_{5}$ & 14.90 & $x_{15}$ & 45.30 \\
\hline$x_{6}$ & 21.40 & $x_{16}$ & 49.70 \\
\hline$x_{7}$ & 26.70 & $x_{17}$ & 50.30 \\
\hline$x_{8}$ & 30.70 & $x_{18}$ & 53.90 \\
\hline$x_{9}$ & 35.00 & & \\
\hline & & & \\
\hline
\end{tabular}


The dual prices of each constraint related to arcs are given in Table 3.

Table 3. The dual prices for each constraint related to arcs

\begin{tabular}{|c|c|c|c|c|c|}
\hline Arc & $\begin{array}{c}\text { Dual } \\
\text { Price }\end{array}$ & Arc & $\begin{array}{c}\text { Dual } \\
\text { Price }\end{array}$ & Arc & $\begin{array}{c}\text { Dual } \\
\text { Price }\end{array}$ \\
\hline$(1-2)$ & -1.00 & $(7-19)$ & 0.00 & $(13-15)$ & 0.00 \\
\hline$(2-3)$ & -1.00 & $(8-9)$ & -1.00 & $(14-16)$ & -1.00 \\
\hline$(3-4)$ & -1.00 & $(9-10)$ & -1.00 & $(16-17)$ & 0.00 \\
\hline$(4-5)$ & -1.00 & $(10-11)$ & -1.00 & $(15-18)$ & 0.00 \\
\hline$(5-6)$ & -1.00 & $(11-12)$ & -1.00 & $(16-18)$ & -1.00 \\
\hline$(6-7)$ & -1.00 & $(12-13)$ & 0.00 & $(17-18)$ & 0.00 \\
\hline$(7-8)$ & -1.00 & $(12-14)$ & -1.00 & $(18-19)$ & -1.00 \\
\hline
\end{tabular}

Critical path including each arc which corresponds a constraint having a dual price of -1 is presented in Figure 2. According to this figure, A,B,C,D,E,F,G,I,J,K,L,P,R,T and V activities are determined as critical activities.

Since this transformer building is a part of tramline project, it is necessary to complete it in 45 days in order to not delay the main project. The crashing cost required to complete project in 45 days is calculated by means of a mathematical model. Crashing is made for critical activities since total float values are zero. Daily crashing costs obtained by using ministry of environment and urbanisation are given in Table 4 for these activities.

Table 4. Critical activities and daily crashing costs

\begin{tabular}{|c|c|c|c|c|c|}
\hline Act & $\begin{array}{c}\text { Daily } \\
\text { Crashing } \\
\text { Cost } \\
\text { (TRY) }\end{array}$ & Act & $\begin{array}{c}\text { Daily } \\
\text { Crashing } \\
\text { Cost } \\
\text { (TRY) }\end{array}$ & Act & $\begin{array}{c}\text { Daily } \\
\text { Crashing } \\
\text { Cost } \\
\text { (TRY) }\end{array}$ \\
\hline A & 80 & F & 850 & L & 545 \\
\hline B & 120 & G & 360 & P & 240 \\
\hline C & 132 & I & 520 & R & 128 \\
\hline D & 160 & J & 732 & T & 230 \\
\hline E & 810 & K & 80 & V & 42 \\
\hline
\end{tabular}

$\mathrm{Y}=\{A, B, C, D, E, F, G, I, J, K, L, P, R, T, V\}$

$\mathrm{Z}=\{H, M, N, O, S, U\}$

$\begin{array}{ll}j: \text { Nodes } & \forall j \in W \\ i: \text { Critical Activities } & \forall i \in Y \\ k \text { : Non-critical Activities } & \forall k \in Z\end{array}$

Decision variables:

$x j$ : the time that the event corresponding to node $\mathrm{j}$ occurs

$t_{i j}$ : the duration of activity on arc $(\mathrm{i}, \mathrm{j})$

$d_{i}$ : the crashing time of critical activity $\mathrm{i}$

$c_{i}$ : the daily crashing cost for critical activity i

$a_{k}$ : the crashing time of non-critical activity $\mathrm{k}$

$\max _{i}$ : the maximum crashing time of critical activity $\mathrm{i}$ $M$ : Big number

$\min$

$$
z=\sum_{i \in W} d_{i} * c_{i}+M * \sum_{k \in Z} a_{k}
$$

(3)

$$
\begin{array}{ll}
x_{j} \geq x_{i}-d_{i}+t_{i j} & \forall i, j \\
d_{i} \leq \max _{i} & \forall i \\
x_{19}-x_{1} \leq 45 &
\end{array}
$$

Objective function for crashing model is given in Equation 3. It aims to minimize crashing cost required to complete the project in 45 days. Constraint 4 indicates time constraints for each node.

The constraints related to maximum crashing times for each critical activity are presented in constraint 5. Constraint 6 ensures completing the project in 45 days. The results of project crashing model obtained from LINGO 17.0 program are presented in Table 5. As seen in this table, the project crashing cost is determined as 1659.4 TRY. Besides, the crashing times of each critical activity are given in this table. After determining the crashing times of each critical activity, we solved the mathematical model again using obtained critical activity durations. As a result of new solution, it is seen that the critical and non-critical activities has not changed.

Indices:

$\mathrm{W}=\{1,2, \ldots, 19\}$

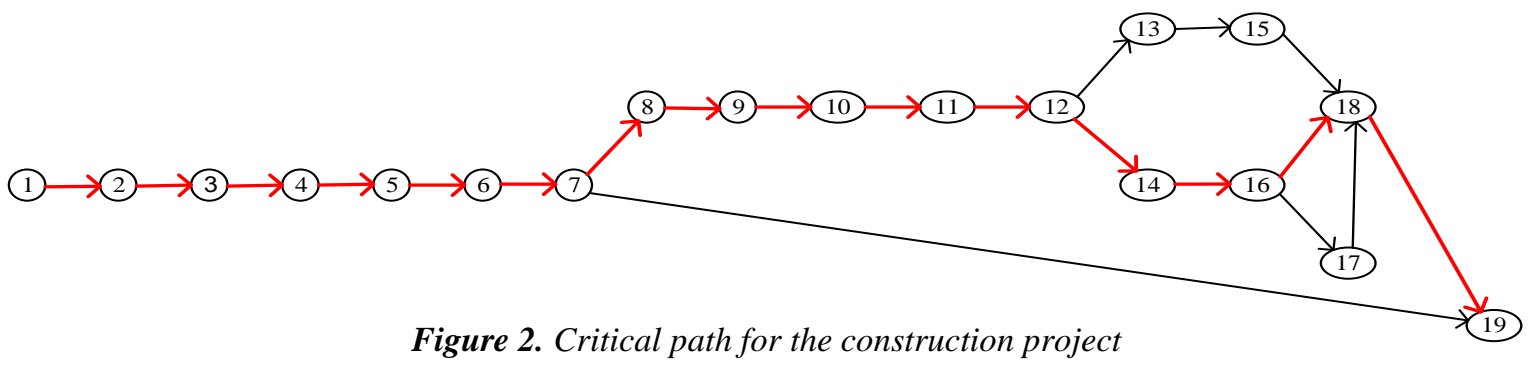


Table 5. Results of the project crashing model

\begin{tabular}{|c|c|c|c|c|c|c|c|}
\hline $\begin{array}{c}\text { Objective } \\
\text { Value }\end{array}$ & 1659.4 & \multicolumn{7}{|l|}{} \\
\hline Variable & Value & Variable & Value & Variable & Value & Variable & Value \\
\hline$d_{A}$ & 1.80 & $d_{L}$ & 0.00 & $d_{U}$ & 0.00 & $x_{10}$ & 34.90 \\
\hline$d_{B}$ & 0.20 & $d_{P}$ & 1.00 & $x_{1}$ & 0.00 & $x_{11}$ & 35.40 \\
\hline$d_{C}$ & 1.20 & $d_{R}$ & 1.00 & $x_{2}$ & 3.00 & $x_{12}$ & 36.50 \\
\hline$d_{D}$ & 1.30 & $d_{T}$ & 1.20 & $x_{3}$ & 3.40 & $x_{13}$ & 38.50 \\
\hline$d_{E}$ & 0.00 & $d_{V}$ & 0.50 & $x_{4}$ & 4.40 & $x_{14}$ & 38.50 \\
\hline$d_{F}$ & 0.00 & $d_{H}$ & 0.00 & $x_{5}$ & 10.40 & $x_{15}$ & 39.10 \\
\hline$d_{G}$ & 1.00 & $d_{M}$ & 0.00 & $x_{6}$ & 16.90 & $x_{16}$ & 41.50 \\
\hline$d_{I}$ & 0.10 & $d_{N}$ & 0.00 & $x_{7}$ & 22.20 & $x_{17}$ & 42.10 \\
\hline$d_{J}$ & 0.00 & $d_{O}$ & 0.00 & $x_{8}$ & 25.20 & $x_{18}$ & 44.50 \\
\hline$d_{K}$ & 0.60 & $d_{S}$ & 0.00 & $x_{9}$ & 29.40 & $x_{19}$ & 45.00 \\
\hline
\end{tabular}

\section{Conclusions and Future Suggestions}

In this study, a transformer building project of a tramline is analyzed using a project management model. Initially, completion time and critical activities were determined through a project planning technique. As a result of mathematical model; expected completion time of the project was calculated as 54.9 days and A, B, C, D, E, F, G, I, J, $\mathrm{K}, \mathrm{L}, \mathrm{P}, \mathrm{R}, \mathrm{T}$ and $\mathrm{V}$ activities were determined as critical activities. Afterwards, a crashing model was developed to transformer building project for critical activities in order to not delay the tramline project. It is aimed to determine the cost required to complete the project in 45 days by means of this project crashing model. The cost of project crashing for critical activities was found as 1659.4 TLs by means of mathematical programming model. It can be said that it is possible to complete the project 10 days earlier with approximately $\% 1$ of total project cost. Besides, this approach can be used for different and bigger projects in order to determine completion time and crashing cost.

\section{References}

[1] W. Winston, Operations Research Applications and Algorithms, 4th ed., 2003.

[2] N. Ibadov, Determination of the Risk Factors Impact on the Construction Projects Implementation Using Fuzzy Sets Theory, Acta Physica Polonica A 130(2016) 107-111. 10.12693/APhysPolA.130.107

[3] L.O. Ugur, A Neuro-Adaptive Learning (NAL) Approach about Costs of Residential Buildings, Acta Physica Polonica A 132(2017) 585-587. 10.12693/APhysPolA.132.585

[4] A. Recioui, Design and Thinning of Linear and Planar Antenna Arrays Using a Binary Teaching Learning Optimizer, Acta Physica Polonica A 130(2016) 7-8. 10.12693/APhysPolA.130.7.

[5] S. Foldes, F. Soumis, PERT and crashing revisited: Mathematical generalizations, European Journal of
Operational Research 64(1993) 286-294. https://doi.org/10.1016/0377-2217(93)90183-N

[6] M.F. Shipley, A. Korvin, K. Omer, BIFPET methodology versus PERT in project management: fuzzy probability instead of the beta distribution, Journal of Engineering and Technology Management 14(1997) 49-65. https://doi.org/10.1016/S0923-4748(97)00001-5

[7] S. Gümüsoglu, H. Tütek, An analysis method in project management using primal-dual relationships, International Journal of Project Management 16(1998) 321-327. https://doi.org/10.1016/S0263-7863(97)00057-4

[8] G.Y. Abbasi, A.M. Mukattash, Crashing PERT networks using mathematical programming, International Journal of Project Management 19(2001) 181-188. https://doi.org/10.1016/S02637863(99)00061-7

[9] T. Yang, Performing complex project crashing analysis with aid of particle swarm optimization algorithm, International Journal of Project Management 25(2007) 637-646.

[10] D. Trietsch, K.R. Baker, PERT21: Fitting PERT/CPM for use in the 21st century, International Journal of Project Management 30(2012) 490-502. https://doi.org/10.1016/j.ijproman.2011.09.004

[11] F. Cebi, I. Otay, A fuzzy multi-objective model for solving project network problem with bonus and incremental penalty cost, Computers \& Industrial Engineering 82(2015) 143-150.

[12] B.H. Tabrizi, S.F. Ghaderi, A robust bi-objective model for concurrent planning of project scheduling and material procurement, Computers \& Industrial Engineering 98(2016) 11-29.

[13] A.H.I. Lee, HY. Kang, TT. Huang, Project management model for constructing a renewable energy plant, Procedia Engineering 174(2017) 145154. https://doi.org/10.1016/j.proeng.2017.01.186

[14] B.G. Soto, A. Rosarius, J. Rieger, Q. Chen, B.T. Adey, Using a Tabu-search Algorithm and 4D Models to Improve Construction Project Schedules, Procedia Engineering 196(2017) 698-705. 